\title{
Cost analysis in the ICU from the standpoint of physical therapy
}

\author{
Liria Yuri Yamauchi ${ }^{1, a}$
}

The study conducted by Rotta et al., ${ }^{(1)}$ published in the current issue of the JBP, analyzed costs by means of an instrument designed in the early 1990s, the Omega score. The first question that comes to mind is "why did they use this instrument?" This question arises for obvious reasons, since time has a clear influence on the economy and on the costs of certain procedures, which can also undergo changes due to modernization. However, in analyzing the topic "cost analysis in the ICU" more closely, we encounter a highly complex theme. In 2002, a report by the American Thoracic Society listed several issues related to cost analysis in intensive care, ${ }^{(2)}$ such as the lack of accurate data for cost analysis; the complexity of the cases; the fact that there is no standardized approach for measuring or valuing costs across countries; the fact that the most commonly used outcomes in ICU studies (e.g., ICU mortality) are not ideal for cost-effective analyses, while preferred outcomes for cost-effective analyses (e.g., long-term quality-adjusted survival) are rarely evaluated; and the burden of critical illness on family members, which is not easily captured in a cost-effective analysis. Complementary to these issues is the reflection made by $\operatorname{Khan}^{(3)}$ : on many occasions, the option with the lowest cost is not the preferred one. For instance, early death may be relatively more economical. In contrast, a costly intervention that saves lives may be acceptable to society if the benefits considered are greater than the increase in costs. This reinforces the notion that cost analysis also depends on several factors, mainly the perspective adopted.

As mentioned by Rotta et al.,(1) the Omega score was developed in France in 1992 and has not been validated for use in or adapted to the currency of Brazil. In addition, the cost of the procedures, as well as the procedures themselves, may have changed over time. As mentioned elsewhere, ${ }^{(2)}$ the lack of standardization for measuring costs across countries is an obstacle to the accuracy of the analyses made. This can be considered a possible measurement bias and underscores the need for instruments that are more accurate in estimating costs in the ICU. However, it is necessary to consider the current scarcity of validated instruments for cost analysis in the ICU.

Although the logarithmic transformation of data in the linear regression analysis presented by Rotta et al. ${ }^{(1)}$ might be statistically acceptable, it limits direct analysis of the results. For instance, we observed that length of ICU stay and severity as measured by the Acute Physiology and Chronic Health Evaluation II were independently associated with increased costs, and that 24-h physical therapy showed an inverse association. However, logarithmic transformation does not allow a direct interpretation of this information on the basis of $\beta$ values. Assessing values in French francs also limits the interpretation of results. A study published by Montuclard et al. ${ }^{(4)}$ used the Omega score with correction for conversion to euro. At that time, one U.S. dollar was equivalent to one euro, which facilitated the interpretation of costs. The issue of temporality once again appears to influence cost analysis, as a result of changes in the economy.

An important consideration regarding the adoption of 24-hour shifts for physical therapy by hospitals would be indirect reduction of costs. As stated by Bürge et al., (5) although adding physical therapy to usual care increases fixed costs, its effects can reduce the costs associated with lost productivity, medication use, or treatments by other health care professionals. An indirect reduction in costs could support the finding of Rotta et al.,(1) who estimated that, despite the increase in the costs associated with the team, hospitalization costs decreased. Their study ${ }^{(1)}$ reiterates the importance of standardized approaches for cost analysis in the ICU. In the future, broader-perspective analyses assessing the impact that interventions in the ICU have on the daily lives of patients and their families will be needed in order to foster public policies aimed at critically ill patients.

\section{REFERENCES}

Rotta BP, Silva JM, Fu C, Goulardins JB, Pires-Neto RC, Tanaka C Relationship between availability of physiotherapy services and $\mathrm{ICU}$ costs. J Bras Pneumol. 2018;44(3):184-9

2. Understanding costs and cost-effectiveness in critical care: report from the second American Thoracic Society Workshop on outcomes research. Am J Respir Crit Care Med. 2002,165(4):540-50. https://doi. org/10.1164/ajrccm.165.4.16541

3. Kahn JM. Understanding economic outcomes in critical care. Curr Opin Crit Care. 2006;12(5):399-404. https://doi.org/10.1097/01. ccx.0000244117.08753.38

4. Montuclard L, Garrouste-Orgeas M, Timsit JF, Misset B, De Jonghe B, Carlet J. Outcome, functional autonomy, and quality of life of elderly patients with a long-term intensive care unit stay. Crit Care Med. 2000;28(10):3389-95. https://doi.org/10.1097/00003246-20001000000002

5. Bürge $E$, Monnin D, Berchtold A, Allet L. Cost-effectiveness of physical therapy only and of usual care for various health conditions: systematic review. Phys Ther. 2016;96(6):774-86. https://doi.org/10.2522/ptj.20140333 